Wood Chemistry: Fundamentals and Applications. Eero Sjöström, Academic Press, New York, 223 p., 1981, US\$22.00, ISBN 0-12-647480-X.

This is a highly informative and very affordable book on wood chemistry. Sjöström deals with an immense amount of highly condensed infórmation in an expert and authoritative manner. The book is very well illustrated throughout, and this adds much to the ease of understanding of the basic chemistry and applications of it in the cellulose industries.

The book takes the approach whereby references to each chapter are given only at the end, thereby achieving a much smoother flow of discussion of the topic. The book reads as an excellent introductory text in this complex subject giving just sufficient background information on each wood component to form a coherent picture.

The book essentially follows a conventional and logical organization in introducing the various wood chemical components. The first six chapters deal with the fundamentals. Rightfully, Chapter 1 recites the macroscopic and microscopic structure of wood. Chapters 2 and 3 deal with carbohydrates in general and chemical and physical properties of cellulose, hemicellulose in particular. Lignin and extractives are treated in the two subsequent short chapters. Chapter 6 deals with the complicated anatomy and chemistry of barks. These six chapters make up almost exactly half of the book's contents.

The applications section of the book expands on fundamentals of the main pulping (Chapter 7) and pulp bleaching (Chapter 8) processes, and of cellulose derivatives in Chapter 9. Wood chemicals and byproducts of the pulping processes are discussed in Chapter 10.

The strength of the book is its skillful condensation of a vast amount of material without simplification. The author manages to impress with much depth and breadth in every chapter excepting Chapter 10 on the treatment on wood chemicals, where the information is rather sketchy. Due to the present interest in conversion of wood into chemical feedstocks, this section might well have been expanded to provide an adequate background into the methods and problems of quantitative decomposition of the wood chemical matrix. While immediate products obtainable from wood sugars are listed, no indication of their industrial ap. plicability is mentioned. It appears that the bulk of the references are dated between 1964 to 1974. This poorly reflects the colossal efforts made recently to understand better the chemistry of wood and to become more cost effective and economical in wood processing. Notwithstanding these shortcomings the book can be recommended highly as an introductory text book on wood chemistry.

\section{Laszlo Paszner}

Faculty of Forestry

University of British Columbia
Environmental Physiology of Plants. A.H. Fitter and R.K.M. Hay, Academic Press, London, 355 p., 1981, US $\$ 19.50$, paperback, ISBN 0-12-257762-0. Also available in hardcover.

This book addresses the $\$ 64000$ ques. tion: "How do the intricate physiological mechanisms which have been elucidated over the last 100 years by plant physiologists really operate under natural conditions?" Successful application of this hard-won knowledge depends entirely on finding satisfactory answers to this question. Filter and Hay perceived the need for an examination of the physiology of plants from an ecological and evolutionary standpoint, and their text is a valuable contribution of the subject. The book is structured to reflect the concept that plants sense the environment in two distinct ways: as a source of energy and materials; and as a compendium of potentially damaging stresses. This latter point may be translated into silvicultural terms: stand performance is growth potential diminished by the in. tegrated effect of all the constraining influences.

In the useful introductory chapter, Fitter and Hay present their views on the physiological basis of ecology under the headings: Favourability and toxicity; Significance of growth rate; Influence of environment; Strategies of response; and Physiological tactics.

Fitter and Hay recognize four possible states for any environmental factor: favourable, unfavourable, neutral, and toxic. The distinction between unfavourability and toxicity in the physiological impact of an environmental factor is made in a particularly enlightening way. Growth, in most species, declines outside a recognizable optimum range of intensity for a given environmental factor. But, say Fitter and Hay, this decline may be for either of two very different reasons: there may be an actual toxic effect, where a factor in excess interferes with metabolism; or growth may simply slow down owing to a deficiency of nutrient ions, light, or water. Many of the species that are apparently adapted to unfavourable habitats will in fact grow better in favourable conditions. The ecological niche of such plants is determined by their low ability to compete and high toleration of extremes rather than by any preference for harsh environments. These matters bear directly on the silviculturist's efforts to manipulate the environment in order to achieve the objectives of management.

As an example of a factor that in laboratory conditions may appear to be neutral and yet have critical ecological effects in nature. Fitter and Hay note that, whereas in laboratory-grown plants, silicon may seem to serve no particular purpose, in nature it provides grasses with support and protection from grazing.

The body of the book is equally divided between Part II, The Acquisition of Resources, and Part III, Responses to Environmental Stress. The latter opens with a chapter on temperature, and continues through chapters on ionic toxicity, gaseous toxicity, and interactions between organisms. The absence of chapters on wind and on water as agents of environmental stress is hard to understand. The environmental stresses resulting from wind, so important in the field and so often ig nored in the laboratory, are considered only to the extent of noting a reference (in the chapter on temperature) to leaf abrasion by wind-blown snow crystals as the primary factor limiting tree development beyond the arctic treeline. It is fair to say, however, that water stresses are discussed in Part III.

The paperback version is attractively produced, and I like the innovation of giving page references in the margin alongside the list of references. The book should stimulate both physiologists and silviculturists to their mutual advantage.

\section{R.F. Sutton}

Weeds, 2nd ed. W.C. Muenscher, Cornell University Press, Ithaca, New York, 586 p., 1980 (re-issue of 1955 ed. with new foreword and appendices by P.A. Hyypio) US $\$ 32.50$, ISBN 0-8014-1266-8.

This work has been described in prestigious botanical journals as "classic", "the most comprehensive and useful book on the common weeds of the northern United States and Canada", "the premier book on the subject for identification and basic natural history of the bulk of the weeds found in the continental United States and Canada", and "an essential reference book for field biologists

The second edition of Weeds gives, for each of 577 weeds, the botanical name (generally following Gray's Manual of Botany, 8th ed.), common name, a thumbnail sketch of the ecological essentials, a concise botanical description, and the recommended method of control. There is a 40-page key to the groups and species of weed, and, for the non-specialist, there are 131 figures and a glossary. The weeds are arranged alphabetically, by scientific name, within families.

The appendices that have been added to the re-issue are: Appendix 1, Changes in botanical nomenclature, including changes in the authorities, published since 1955; Appendix II, Weeds mentioned in the book, arranged alphabetically by botanical name followed by the "standardized" common name; and Appendix III, Bibliography of the literature used in compiling Appendices I and II.

Weeds would be very useful to foresters working in old field situations, but only a handful of forest weeds are covered. A more appropriate title would have been Agricultural Weeds.

Within that ambit, the book fully deserves the plaudits that have been bestowed upon it. It does not, nor is it intended to, compete with more detailed accounts of individual weeds as, for example, the 32 weeds described in the 380-page The Biology of Canadian Weeds (Agriculture Canada Publication 1693, 1979). In what it sets out to do, Weeds is in a class of its own.

\section{R.F. Sutton}


Regional Silviculture of the United States, 2nd ed. J.W. Barrett, Wiley. Interscience, New York, 551 p., 1980, \$29.40, ISBN 0-471-05645-6.

As with the first (1962) edition, the basic idea of the second edition of Regional Silviculture... is the assessment of the significant biological, physical, and economic qualities of the various forest regions, together with a description of how these qualities affect silvicultural practice. Each region is accorded a chapter prepared by a silviculturist familiar with that region.

Of greatest direct interest to Canadians will be regions that abut our forests: the Northeast, Lake States, Pacific Northwest, Alaska, and Northern Rocky Mountain. The other regions covered are: Central, Southern Hardwood, Southern Pine, Middle and Southern Pine, Middle and Southern Rocky Mountain, and California. Hawaii is not mentioned. The obvious test that can be applied to work of this kind is to see how well the text reflects what the reviewer knows about the areas with which he or she is most familiar. By this limited test, Regional Silviculture... does very well.

The book under review invites com. parison not only with its first edition but also with R.H. Westveld's Applied Silviculture in the United States (1939, Wiley, New York, 2nd ed. 1949). It seems odd that, in spite of the common subject matter, and the many similarities between the two works, nowhere is Westveld's book cited in Regional Silviculture ... Certainly, Westveld could be disconcertingly direct on occasion, e.g." "The entire forest area [of the Lake States] . . . has been badly managed... Because of this carelessness and lack of interest in the future of the land, approximately 14000000 acres of forest land [( $25 \%$ of the total)] is either devoid of any tree growth or supports only a poor to fair stand of reproduction." In Regional Silviculture ...., however, Hansen, who contributes the chapter on the Lake States region, blames not the loggers but the farmers and land-cleaning for the sorry state of affairs.

Both Westveld and Barrett perpetuate the myth that "the spruces are shallowrooted"', whereas the truth of the matter is that spruces have remarkably plastic root systems that permit the development of shallow, plate-like root systems on soils where the rooting zone is limited by hardpan, rock, mechanical impedance, or lack of aeration, but that also allow exploitation of deep soil layers on other sites.

As Editor Dr. Barrett notes, the attempt to achieve consistency between the various regional accounts has been more successful in the second than in the first edition. Nevertheless, there is still room for improvement, though the great diversity between the regions creates considerable difficulty in this regard.

On the debit side, the photographic figures are generally pallid, ghostly things (much inferior to Westveld's photographs, for instance), scales are omitted from several of the maps, and, in my copy, pages $277 / 278$ are duplicated at the expense of pages 293/294, which are missing.

In summary, however, the immensely difficult job of covering a subject as broad and as diverse as the regional silviculture of area the size of the United States has been accomplished with a remarkable degree of success.

\section{R.F. Sutton}

Interactions Between Herbicides and the Soil. R.J. Hance (Ed.) Academic Press, London, 349p., 1980, US\$49.50, for the European Weed Research Society, ISBN 0-12-323840-4.

In the Preface to this excellent book, Dr. Hance succinctly describes the purpose:

"This book is an attempt ... to summarize the available information and then suggest where the most important gaps lie with respect to agricultural practice, legislation and academic science". And: "This book deals first with what could be termed the processes, physical, chemical and biological, which act upon a herbicide in the soil, and then goes on to consider the biological consequences of the presence of the herbicides in the soil with respect both to the crop and the soil." And: "The aim ... is to be useful to the active scientist, the research administrator and to those concerned with regulation."

The summary, which is rendered in English, French, and German, is a valuable appreciation of the ten high quality chapters contributed by members of the Herbicide/Soil Working Group of the European Weed Research Society.

A notable feature of the book is that, although each is attributed to only one or two authors, every chapter has been reviewed by all the contributors. This, plus Dr. Hance's editorial sureness, has produced a balanced treatment of the subject matter rarely found in volumes of this kind.

A listing of the chapter titles will indicate the scope and caliber of the book: Adsorption phenomena (Calvet), Transport in solution (Leistra), Transport in the vapour phase (Hance), Persistence and its prediction (Hurle and Walker), The study of transformations (Guth), Role of microorganisms in decomposition (Torstensson), Plantavailability and uptake of herbicides from the soil (Schmidt and Pestemer), Activity and selectivity in the field (Walker). Effects on soil microflora (Greaves and Malkomes), and effects on soil fauna (Eijsackers and Van De Bund).

Forest use of herbicides is not covered in this book, but in matters of soil science and weed science agriculturists have always been rotations ahead of the forester. Anyone concerned about what happens to a herbicide when it reaches the ground, whether field or forest, would be well advised to obtain a copy of this book, but, although Dr. Hance's point that "all is not ignorance and doubt" is well made, don't expect to find all the answers here.

\section{R.F. Sutton}

A Field Guide to Atmosphere. Vincent J. Schaefer and John A. Day, Houghton Mifflin, Boston, 359 p., 1981, \$18.25. ISBN 0-395-24080-8.

There is little question that the Peterson Field Guides have played a major role in making the out-of-doors the great playground of our increasingly urban society. This book is the twenty. sixth in this time honored series which has helped so many of us identify the birds, flowers, and animals of the forests in which we work. I was intrigued when I received it: upon first examination, I assumed it was a guide to the weather. While this is basically true, that first impression falls short. The authors have probably entitled their work "A Field Guide to the Atmosphere" rather than the weather because they wanted to avoid the image and use accorded a pocket weather forecaster. They have succeeded almost too well for, while the book contains the usual plethora of photographs and figures (336 b and w, 32 colour, and 45 line drawings), it has a substantial textbook flavor which is reinforced by a 38-page chapter of "simple experiments".

This book includes the expected chapters dealing with clouds, precipitation, and severe weather phenomena. These are clear and well written. It also contains interesting sections on unusual cloud patterns, a general discussion on the vertical development of the atmosphere, and a view of clouds from aircraft and satellites. A section on atmospheric color is almost too detailed, and the two short chapters on particulate matter and weather modification left me wondering if perphaps this was a simplified college text rather than a "field" guide. While it contains some of the standard symbols used on weather maps, the appendix is far from complete, and there is no discussion of how to read a weather map or decode a weather report.

The strong point of the book is its illustrations. Black and white photographs comprise half of the book. They are well chosen and exceptionally well captioned. Two groupings of photographs are especially interesting: the satellite photos (P1.8-25), and classification plates ( $\mathrm{P} 1.26-40)$. These latter are very well labeled and titled and should be a great help to the novice.

This book will help the amateur understand atmospheric phenomena, but it is not a carry-in-the-packsack field guide in the traditional sense. While my wildflower and bird books live in my camera bag during the summer, I doubt that this volume will ever leave my office. This is a good, well written book on a highly complex subject and I recommend it to any serious weather watcher. I would consider it to be a basic reference for the professional in fire control, and I highly recommend it to teachers and students of forest meteorology and climatology. It should play an important role in helping improve the forester's understanding of the atmosphere.

\section{T.G. Eiber}

School of Forestry, Lakehead University Thunder Bay, Ontario 
Air Polltion and Forests: Interactions Between Air Contaminants and Forest Ecosystems. William H. Smith, SpringerVerlag, New York. 379 p., 1981, US\$29.80. This review is adapted from that appearing in the March, 1982, Vol. 63 No. 3, issue of the Bulletin of the American Meteorological Society, whose permission to publish is acknowledged with thanks).

For the 1972 annual meeting of the American Association for the Advancement of Science, William H. Smith was asked to review current knowledge on the relationship between air pollution and forests. The present volume is an uncritical updating of that literature review to January 1980. Smith relies principally on data from North American sources.

Each of the three sections of the volume deals with a class of interactions: Class I interations are those in which the forest acts as a source or sink for atmospheric pollutants; Class II interactions involve sub. tle adverse effects on the forest; and Class III interactions induce morbidity or mortality in certain species.

Class II interactions have the greatest impact because,with or without visible injury, they may reduce photosynthesis over a vast area. One field study of the response of radial growth in spruce, subjected to am. bient sulfur dioxide at $0.19,0.05$, and 0.04 ppm, recorded reductions of 45,27 , and $18 \%$ respectively over a nine-year period. After reviewing the effects of all major gaseous pollutants, Smith concludes that two, sulfur dioxide and ozone, are effectively reducing forest growth over widespread areas. A third, fluorine, is important locally.

Acid precipitation, says Smith (in contrast to many writers), has not been demonstrated to promote or reduce forest growth significantly. Toxic mineral dusts appear to have little effect except in extreme concentrations.

Class III interactions, although most apparent locally, have a minor effect on the forest as a whole; they do, however, provide an index of the relative sensitivity to air pollution of various plant communities. A study conducted in the early ' 60 s showed that in the sulfur dioxide plume downwind of the Wawa, Ontario, iron-ore smelter, the eco-system had been peeled off in layers. Beyond $37 \mathrm{~km}$, the tree stratum was intact; within $37 \mathrm{~km}$, it was discontinuous; within $27 \mathrm{~km}$, shrubs replaced trees; within $19 \mathrm{~km}$, the shrubs yielded to herbs; and within 8 $\mathrm{km}$, the land was largely devegetated and the resulting bare surface badly eroded. This study suggests that forests are among the ecosystems most sensitive to damage by air pollutants.

Every aspect of the interaction between air pollution and forests as presented in the literature is examined. Certain areas, such as the effect of air pollution on the insects and pathogens that attack trees, have remained virtually unexplored. Otherwise, the author covers everything from forestgenerated aerosol to the effect of pollution on mycorrhizae and the evolution and deposition of $\mathrm{CO}_{2}$ and $\mathrm{CO}$. For those interested in delving deeper into the subject than this comprehensive but superficial review, the author includes many references at the end of each chapter.
The book contains a few typos and errors. It is disconcerting to find on p. 1 that $95 \%$ of the atmosphere lies below $8-12 \mathrm{~km}$ or on p. 83 that pollen concentration is reduced $80 \%$ inside a forest. It is simply untrue to state, as on p. 198, that Frankia has not been isolated from soil or that Koch's postulates have not been fulfilled. The data presented belie Smith's conclusion that trees have a significant air-cleaning potential. Yet, as far as this reader could ascertain the review for the most part is a reasonably accurate and complete assessment of knowledge up to January 1980.

Smith appears to have a dual writing personality. The core of the book is wellwritten, but the first few chapters and the conclusion contain an abundant array of split infinitives and vague or redundant adverbs. One tires of "very variable", "extremely variable", "very significant", "particularly prevalent", and so forth. I also object to the use of "particulate" as a noun. This jargon from the field of air pollution makes one wonder whatever became of the word "particle". I am reminded of those pedagogues who utilize rather than use use.

The book is well bound and clearly printed, with legible figures and an attractive cover. I recommend it to anyone who would like a thorough overview of the in teraction between air pollution and forests.

\section{James B. Harrington}

Petawawa National Forestry institute Chalk River, Ontario

\section{Silvicultural Equipment Reference Catalogue for Northern Ontario. C.R.} Smith, Ontario Ministry of Natural Resources Branch, unpaginated leaflets in 4-ring binder, 1979, $\$ 25.00$ (inclul. binder) or $\$ 1.00$ per individual leaflet. Available from Public Service Centre, Ontario Ministry of Natural Resources, Room 1640 Whitney Block, Queen's Park, Toronto, Ont., M7A 1W3. Also Silvicultural Equipment Reference Catalogue for Southern Ontario, 1981, by the same author and publisher, in the same format, also $\$ 25.00$ (incl. binder) or $\$ 1.00$ per leaflet.

These two large $(32 \mathrm{~cm} \times 28 \mathrm{~cm})$ catalogues are the impressive outcome of action initiated by the Mechanical Development Committee (Chairman A. Citro) of the Ontario Ministry of Natural Resources (OMNR). The basic purpose was to facilate the development of mechanized silviculture in the province. The preparation of two catalogues, Northern and Southern, was in recognition of the significant differences in silvicultural practice between the northern and southern parts of Ontario.

Each individual type of equipment has been accorded a separate leaflet, mostly four pages long, printed on heavyweight ledger stock, and separated by sturdy (tabbed) railroad board into alphabetically designated sections within which leaflets are numbered sequentially. The 10 sections of the Northern Catalogue are: A. Seeders; B. Blades/Blade Attachments; C. Plows; D. Discs; E. Non-powered Scarifiers; F. Scalpers; G. Chemical Applicators; H.
Specialized Hand Tools; I. Miscellaneous; and J. New and Developmental. The $8 \mathrm{sec}$ tions of the Southern Catalogue are: A. Tree Planters; B.Plows; C. Disc Plows; D. Brush Cutters; E. Pesticide Applicators; F. Fertilizer Applicators; G. Pruning Tools; and H. New and Developmental.

The work of preparing the reference catalogues began with an inventory of existing equipment, District by District, and continued with OMNR staff consultations across the province. Field observations were made wherever possible.

Each leaflet is a mine of concentrated information. An outline of one of the leaflets, chosen at random, will illustrate the richness of the ore. The four-page leaflet B. 1 of the Northern Catalogue, for instance, describes the Blade Rake: Fig 1 is a photograph of a blade rake mounted on the straight blade of a crawler tractor, and the model designation, manufacturer (address, telephone and telex numbers), distributor (address, etc.), price (Can\$, 3 models), current OMNR users (number of units, by District), and total number of units, are given in the preamble. Then follow: Technical Information (including manufacturer's catalogue no., Caterpillar models with which used, width of rake with both straight and angling dozers, number of teeth, clear spacing tooth spacing with both straight and angling dozers, tooth penetration, shipping weight, and optional brushguard height; special modifications, prime mover, horsepower requirements, attachment, additional equipment, transport between sites both rake only and rake with prime mover); How it Works (with a general description of the unit, working principle, and a description of the task performed); Present Uses; Where it is Used (in terms of topography, soil, residual stand, debris, etc., and major site limitations); Operational Information (including staff needed for operation and supervision, safety aspects, maintenance/repairs, parts availability, examples of production rates, and examples of operating costs); and Users' Assessment (advantages and disadvantages as expressed by experienced field staff, but not based on actual field measurements or comparisons).

The value of such readily accessible information is inestimable, and the leaflets collectively constitute a resource of great potential utility. The catalogue should not only improve the use made of the existing equipment, but should also encourage the silviculturist to aim for greater sophistication in silvicultural prescriptions and better monitoring of the results achieved.

The only cautionary note that I would sound is that regular and rigorous updating must be carried out if the value of the catalogue is to be maintained. Perhaps ongoing revision could be accomplished by means of a computerized inventory control, with up-to-the-minute printouts available on demand. Up to this point, however, a difficult but most worthwhile undertaking has been carried through great success.

R.F. Sutton 